Article

\title{
Success Factors for the Implementation of Community Renewable Energy in Thailand ${ }^{\dagger}$
}

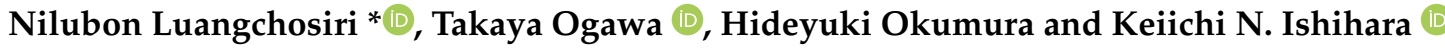 \\ Graduate School of Energy Science, Kyoto University, Kyoto 6068501, Japan; \\ ogawa.takaya.8s@kyoto-u.ac.jp (T.O.); okumura@energy.kyoto-u.ac.jp (H.O.); \\ ishihara.keiichi.6w@kyoto-u.ac.jp (K.N.I.) \\ * Correspondence: luangchosiri.nilubon.t72@kyoto-u.jp; Tel.: +81-080-8471-6522 \\ + This paper is an extended and revised article presented at the International Conference on Sustainable Energy \\ and Green Technology 2019 (SEGT 2019), Bangkok, Thailand, 11-14 December 2019.
}

Citation: Luangchosiri, N.; Ogawa,

T.; Okumura, H.; Ishihara, K.N.

Success Factors for the

Implementation of Community Renewable Energy in Thailand. Energies 2021, 14, 4203. https:// doi.org/10.3390/en14144203

Academic Editors:

Vincenzo Costanzo and Tapas Mallick

Received: 23 April 2021

Accepted: 7 July 2021

Published: 12 July 2021

Publisher's Note: MDPI stays neutral with regard to jurisdictional claims in published maps and institutional affiliations.

Copyright: (c) 2021 by the authors. Licensee MDPI, Basel, Switzerland. This article is an open access article distributed under the terms and conditions of the Creative Commons Attribution (CC BY) license (https:/ / creativecommons.org/licenses/by/ $4.0 /)$.

\begin{abstract}
Community renewable energy (CRE) has recently been proposed as one of the effective policy tools to make a community sustainable and to strengthen this association. CRE is, however, not widespread yet in Thailand, and evidence-based research on CRE in the country is rather scarce. This paper aims to investigate the characteristics of CRE in Thailand to identify the key factors affecting its implementation. Data were collected through semi-structured interviews and document analysis for 26 active CRE projects in Thailand. Results show that the characteristics of CRE in Thailand are rooted in the geographical location of a community. A legal structure was created from a pre-existing group to implement a CRE project. The primary motivation for implementing CRE is sustainable development of a community. We examined essential factors separated into two groups-internal and external factors - in reference to CRE in developed nations. We highlight several issues concerning the further development of CRE in Thailand. First, a strong group leader and a formal structure are essential to drive and manage a project. Second, networks of CRE projects and long-term revolving funds are crucial external support to implement CRE.
\end{abstract}

Keywords: small-scale; success factor; community renewable energy; sustainable energy

\section{Introduction}

In the modern world, the dominant paradigm of energy supply and production consists of a centralized, usually fossil-fuel-based energy production that generates energy remotely and supplies it to consumers over a vast region. As an alternative to this paradigm, in recent years, there have been efforts to establish decentralized, community-owned, small-scale facilities that produce energy from renewable resources. One of the movements following this paradigm is community renewable energy (CRE).

CRE offers communities the ability to tackle poverty and raise the standard of living [1-3]. Many studies have argued that various socioeconomic benefits are to be gained from the production and use of renewable energy (RE) resources at the community level [4-10]. These benefits include job creation, income generation, self-sufficient energy supply, social cohesion, and human capacity development. CRE projects in agricultural communities help increase farm productivity and rural sustainability [6]. However, establishing a CRE project involves many issues, such as financial, organizational, technical, and extensive cooperation [11]. Additionally, CRE requires contribution (e.g., capital, labor, commitment, trust) from community members to drive a project to run [12-14]. Using locally available RE resources requires collective actions and agreements among community members [15]. The crucial factors for a CRE project's success might differ in the different contexts of communities [13,16-19], which then require contrasting support structures for CRE implementation. 
Researchers have intensively investigated the key characteristics and factors affecting CRE development in developed countries/regions, such as the UK, Denmark, Scotland, Germany, and Australia [13,17,20-22]. G. Seyfang et al. examined the strengths and weaknesses of the UK's CRE [17]. They conducted a web-based survey of the CRE projects undertaken between June and October in 2011. Their results highlighted that CRE is a diverse sector: their multiple objectives need joined-up thinking among governmental departments. Networking among groups and monetary policy support are essential factors driving CRE development. Another research investigated the effect of financial incentives on CRE development in Germany, Denmark, the UK, and Ontario [20]. The study argued that appropriate monetary policy support at each stage of CRE development helps communities overcome project setbacks. Network support among CREs is also vital for sector development, as in the case of the Samso renewable energy island in Denmark [13].

In contrast, there are a limited number of papers that explore the factors affecting the deployment of CRE projects in developing countries. A study assessed the impact and identified drivers of and barriers to CRE success by analyzing two community microhydroprojects in Indonesia [18]. The results showed positive socioeconomic impacts, and the essential factor is the intermediary organization's role in supporting project development. E. Macabebe et al. investigated key factors to achieve community-based SHS (solar home system) adoption and sustainability in the Philippines [23]. The results showed that giving priority to the economic value of the technology, capacity building of locals on the technical aspect, management perspectives of the project, and creation of a supply chain for replacement parts are crucial factors for the sustainability of programs. Another study identified factors that influence the success of a rural electric cooperative case in Costa Rica [24]. They argued that six factors affecting success are community governance, capacity building and engagement, ownership structure, technical design, operation and management, and system and project sustainability measures.

Evidence-based research on a community-led initiatives strategy is limited in Thailand as a developing country. A few studies have focused on Thai CRE development. One study involves exploring various aspects of best management practices (BMPs) for sustainable CRE [25]. Results indicated that the key concept of BMPs for sustainability in smallscale CRE is the "actual problem-based solving approach", which will help CRE avoid the creation of unintended negative impacts and develop effective RE implementation. Another study identified how CRE contributes to sustainable energy transitions in Thailand and the Philippines [26]. The article highlighted that valuable insights can be generated from rural- and community-driven renewable energy initiatives and underscored their power to reimagine the future of energy systems in the Global South. Previously, there was a study [9] analyzing financial issues in developing CRE in Thailand in 26 projects, which are also used in this study. The results showed the benefits of CRE projects to the local economy to be income generation, expense savings, and environmental protection; however, they did not focus on factor analysis. Despite the benefits identified, there is still a lack of a comprehensive view on the characteristics and critical factors of implementing CRE projects in Thailand. Thus, there is no basis on which support structures can be built by either communities themselves or the academe or government. Moreover, there are a limited number of studies in developing countries: two cases in Indonesia [18], three cases in the Philippines [23], and one case in Costa Rica [24]. Therefore, it is essential to identify the barriers and drivers of community-led initiatives for energy production in Thailand.

This study, hence, aims to identify factors that lead to successful implementation of Thailand's CRE. We also discuss the factors via a comparison with those in developed nations and identify potential issues and solutions. The results will contribute to the knowledge necessary for informed policymaking, practical knowledge exchange, and research collaboration between CRE stakeholders. 


\section{Data Collection}

\subsection{CRE Subsidy Program in Thailand}

In 2013-2016, the Ministry of Energy (MOEN) of Thailand launched a CRE subsidy program (total of THB $60 \mathrm{M}$ (million) or approximately USD $1.7 \mathrm{M}$ budget) to support the development of CRE using a variety of renewable energy technologies. The objectives of the projects were to identify the necessary financial and technological support for CRE. The MOEN subsidized the project investment to reduce the payback period for a CRE project to less than 3 years.

In this subsidy program, "CRE" was defined as "renewable energy (RE) utilization in the community", where:

- Community members invest either purely financially or with in-kind contributions.

- Resources in the community are used for energy production.

- The energy produced should be traded or self-utilized.

- An entity is formed within the community to govern the project.

Communities that meet the criteria can submit a proposal to garner financial support from the program. Forty-eight CRE projects out of 75 proposals passed the MOEN criteria, while 27 projects were rejected due to lack of technical or economic feasibility. The rejected proposals could be revised and resubmitted to the MOEN before the deadline of proposal submission. Finally, 26 CRE projects were implemented, and the remaining 22 projects canceled their contracts due to several reasons, for example, an unstable market of the product of the project $(25 \%)$, lack of financial resources $(19 \%)$, uncertainty of project success $(19 \%)$, inability to form a legal entity $(13 \%)$, and others (25\%). The overall schedule of the CRE subsidy program in Thailand is shown in Table 1.

Table 1. Schedule of the CRE subsidy program in Thailand.

\begin{tabular}{ccc}
\hline Timeline & Activities & Community Participation \\
\hline July 2013 & Program dissemination and call for proposal in 6 regions & 632 persons \\
\hline \multirow{2}{*}{ August 2013-September 2016 } & Consultation in the communities & 147 communities \\
& Preliminary assessment of RE resources, technology, & and economics \\
\cline { 2 - 3 } August 2013-October 2016 & Proposal development and submission & 75 communities \\
\cline { 2 - 3 } & Screening and approval of the proposal & 48 communities \\
\hline
\end{tabular}

\subsection{After-Action Review (AAR)}

Successful implementation of CRE is highly dependent on the local context of communities and the vast societal structures and institutional arrangements of a project itself. Seyfang and Haxeltine emphasized the importance of resolving internal and external factors in grassroots innovations [27]. Wirth employed an institutional theory to analyze the emergence of a community-based energy project in the concrete local, internal context of a community in Italy [28]. He also suggested the importance of external factors along with his analysis. These factors and their inter-relations should be understood in detail if we want to realize the specific reasons why particular community energy projects succeed or fail. Thus, in this study, we follow Wirth's suggestion to study the concrete internal context and combine it with the external context of CRE in Thailand.

Our research approach involves qualitative content analysis [29] using document analysis and lesson-learned discussions with key actors determined via an after-action review (AAR) technique [30] and semi-structured interviews (SSIs) [31]. Permission to access 26 unpublished proposals was given by the MOEN of Thailand. The data included information about technology type and design, scale, objective, ownership, and mode of organization. Background knowledge allowed us to more deeply understand when, where, 
and why a community created a CRE project, which provided a sound basis for subsequent data collection.

The extraction of success factors involved the AAR technique and SSIs. Although SWOT (strengths, weaknesses, opportunities, and threats) analysis is widely used to identify key factors that have an impact on CRE development in the UK [17] and to evaluate renewable energy projects in Thailand [32], it is not suitable for our objective analysis. SWOT analysis provides a strategic planning framework to evaluate an organization, a plan, a project, or a business activity [33]. On the other hand, AAR is a systematic method that helps individuals learn significant lessons from successful experiences and apply them to others [30]. AARs have three functions for learning from experiences: (i) self-explanation, (ii) data verification, and (iii) feedback. The self-explanation function enables individuals to analyze their behaviors and to suggest explanations for their success and/or failed actions. The data validation function enables learners to cross-validate the information they hold before changing or correcting their mental models. The feedback function enables learners to confirm, add to, overwrite, tune, or restructure information. The main advantage of feedback is that it concentrates not only on performance outcomes but also on the process of task performance [30]. Thus, the AAR approach is appropriate for our analysis objective.

AAR was conducted twice. The first AAR was conducted in Chiang Mai, Thailand, on 24 October 2016 for a preliminary survey. Twenty-one representatives from 10 CRE cases participated in discussions. The authors and the MOEN's staff participated in and facilitated the AAR. The second AAR was conducted in Bangkok, Thailand, on 16 November 2016 to identify key factors influencing CRE implementation. Thirty-seven representatives from $26 \mathrm{CRE}$ cases participated in the AAR. The MOEN's staff facilitated the $\mathrm{AAR}$, and an author was a participant, observing the activity. The AARs were recorded and then subsequently transcribed. Each AAR meeting took about $3 \mathrm{~h}$. All the data collected through documents and interviews were analyzed qualitatively or semi-quantitatively. The overall flow of the AAR process is shown in Table 2.

Table 2. The AAR process.

\begin{tabular}{cc}
\hline \multicolumn{1}{c}{ Steps } & Activities \\
\hline Introduction $(40 \mathrm{~min})$ & $\begin{array}{c}\text { The main facilitator explains the objective and process of the AAR } \\
\text { meeting and questionnaires and divides the participants into } 4 \text { groups, } \\
\text { namely, community enterprise, cooperative, local authority, and } \\
\text { foundation. Each community answers the questionnaire. }\end{array}$ \\
\hline Brainstorming $(40 \mathrm{~min})$ & Brainstorming in the group based on the answer. \\
\hline Presenting the results of brainstorming $(15 \mathrm{~min})$ & $\begin{array}{c}\text { The participants present the ideas generated during the } \\
\text { brainstorming session. }\end{array}$ \\
\hline Summarizing the AAR $(40 \mathrm{~min})$ & $\begin{array}{c}\text { The main facilitator consolidates the ideas obtained from the } \\
\text { brainstorming with the help of all the participants. }\end{array}$ \\
\hline
\end{tabular}

\section{Analysis of Collected Data}

3.1. Characteristics of CRE Projects in Thailand

3.1.1. Detail of Community Energy Groups and Projects

The 26 pilot CRE projects are located in 15 provinces across Thailand, as shown in Figure 1. Overall, most CRE projects are in the northern and southern parts of the country. This is mostly due to the strong network support from academic institutions in the areas. Few projects are located in the central, eastern, and northeastern regions. It seems that CRE's network support from an academic institution strongly affects the number of CRE projects implemented in an area. The average networking of CRE was 1.15 partners per project. 


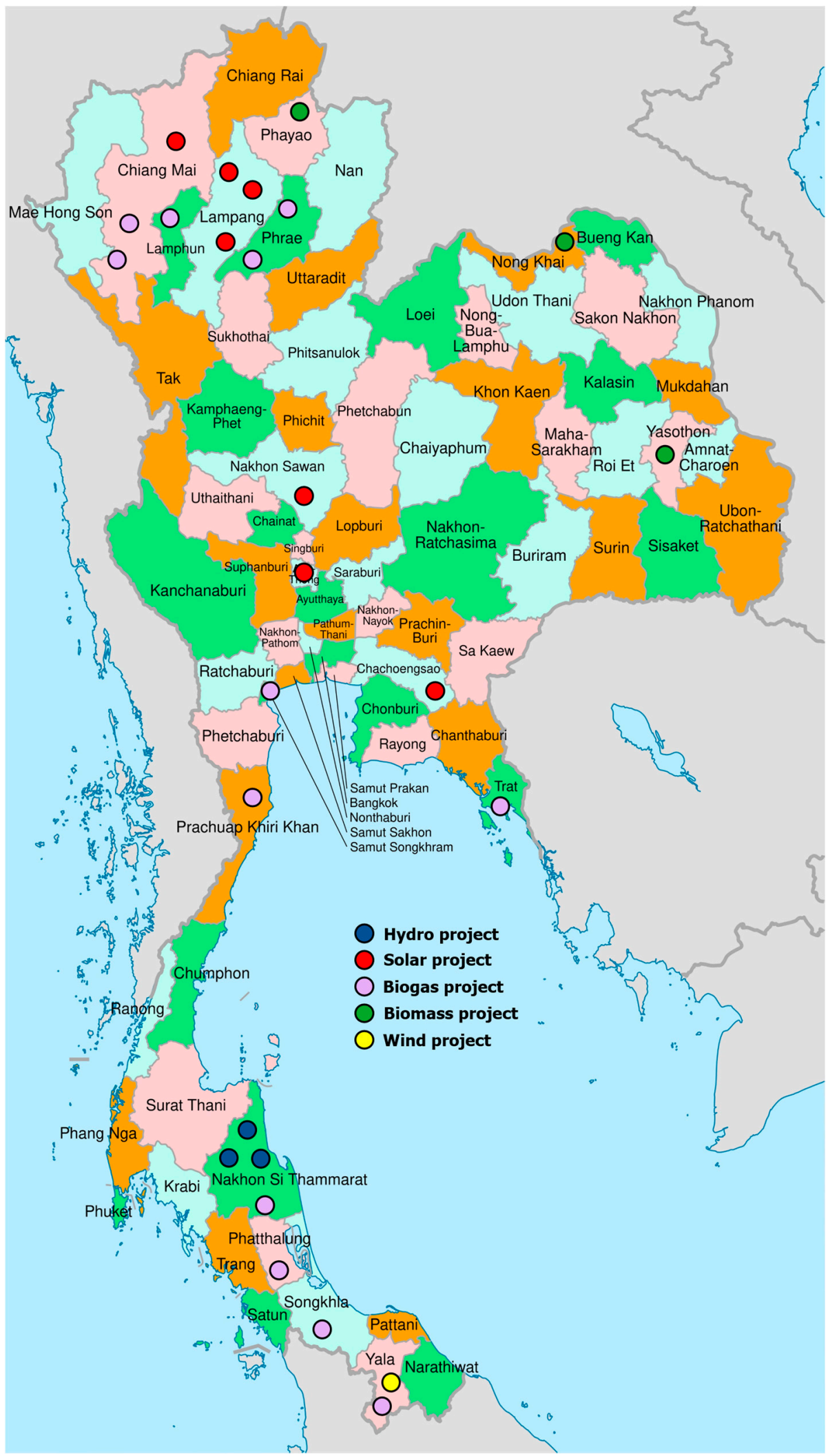

Figure 1. Map showing the geological location of the 26 CRE projects in Thailand: Adapted from [34].

Figure 2a shows the energy generation activities of the 26 CRE projects. Biogas thermal and solar thermal technologies are the most commonly installed technologies due to the fitting of their thermal demand with cost-effectiveness. Most of the CRE projects are implemented in agricultural communities. Thermal energy is needed for agronomic 
activities. Few projects are involved in electricity generation mostly because of communal accesses to the national grid. CRE that generates electricity is only located in an off-grid area or regions with unstable electricity supply.

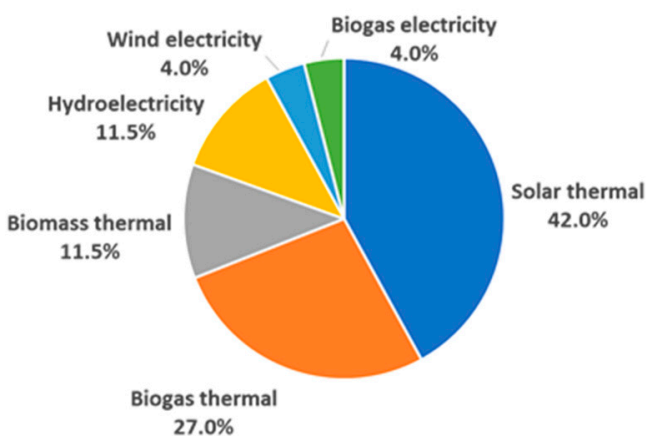

(a)

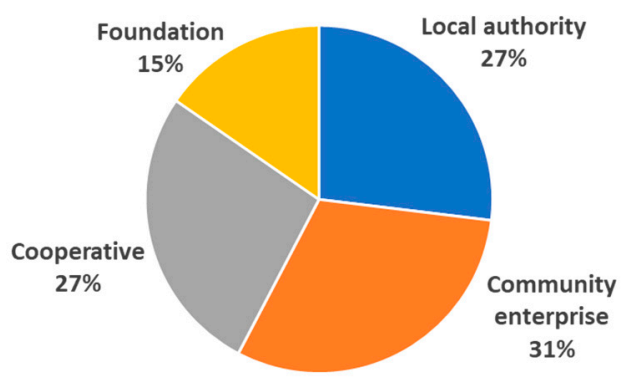

(b)

Figure 2. Detail of community energy projects: (a) Energy generation activities and (b) group types of the 26 CRE projects.

Figure $2 \mathrm{~b}$ shows the types of legal entities that implemented the CRE projects in Thailand. All the CRE projects had a formal structure before implementing the project. We found that the origin of most of the groups is rooted in civil society. The legal entities of the CRE projects were established and invested by local people and existing groups coming together.

\subsubsection{Objectives of CRE Projects}

Figure 3 shows the objectives of CRE project development. Three groups are categorized according to aims: economic, environmental, and social. The most common goal was saving money on energy bills, accounting for $85 \%$ of the groups. For example, biogas projects used gas to substitute LPG or wood for cooking or agricultural activities. The second common goal was improving the local environment, accounting for $50 \%$. For instance, biogas projects focused on reducing odor pollution and underground water contamination in the area. As regards the third objective, 31\% implemented CRE for education in the community. In brief, the economic and environmental dimensions are the main objectives for implementing CRE.

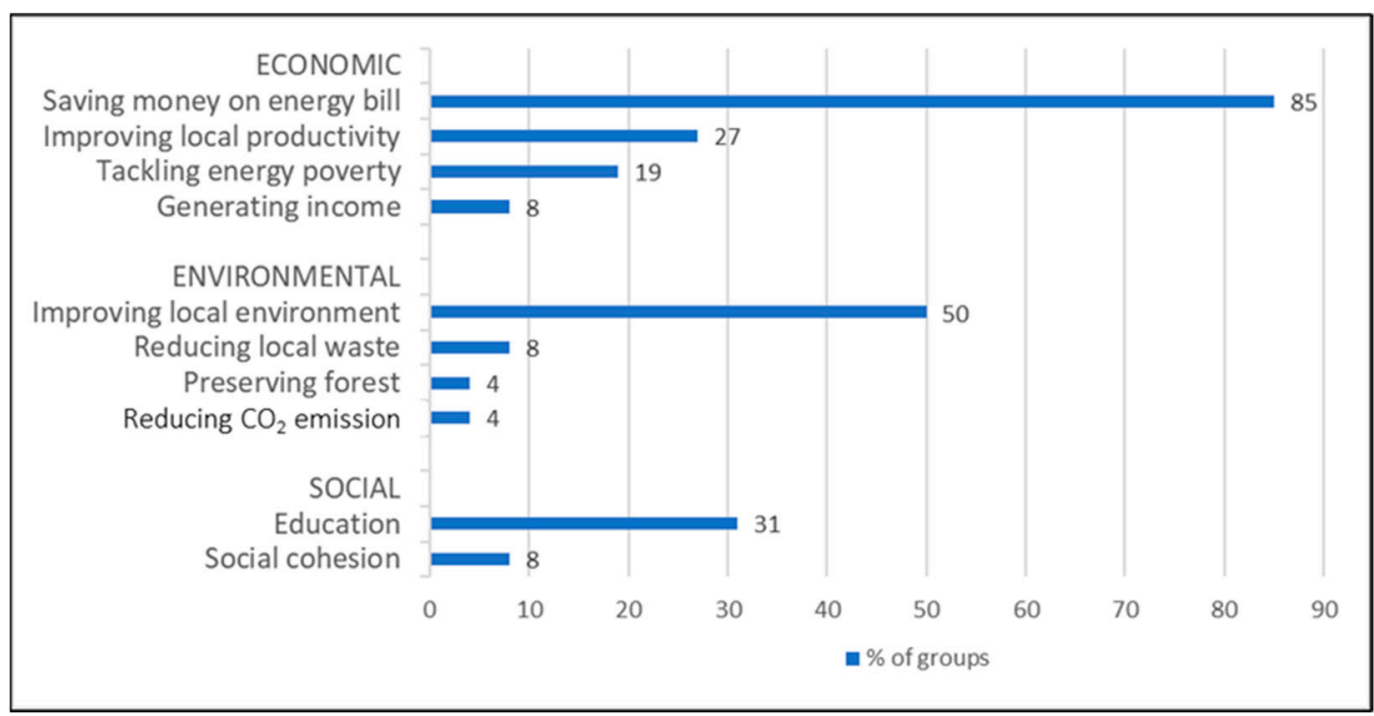

Figure 3. Objectives of Thai CRE groups. 


\subsection{Key Success Factors for the Implementation of CRE Projects}

The key actors identified nine factors that could have influenced CRE implementation. The nine factors can be then categorized into two groups: internal and external. Upon considering the CRE development step, each internal factor is allocated to each step that requires it inside the community, as shown in Figure 4. On the other hand, the external factors mainly are supports from outside the community, which are also assigned to the required step, as shown in Figure 4. Details of the internal and external factors are introduced in the following sections.

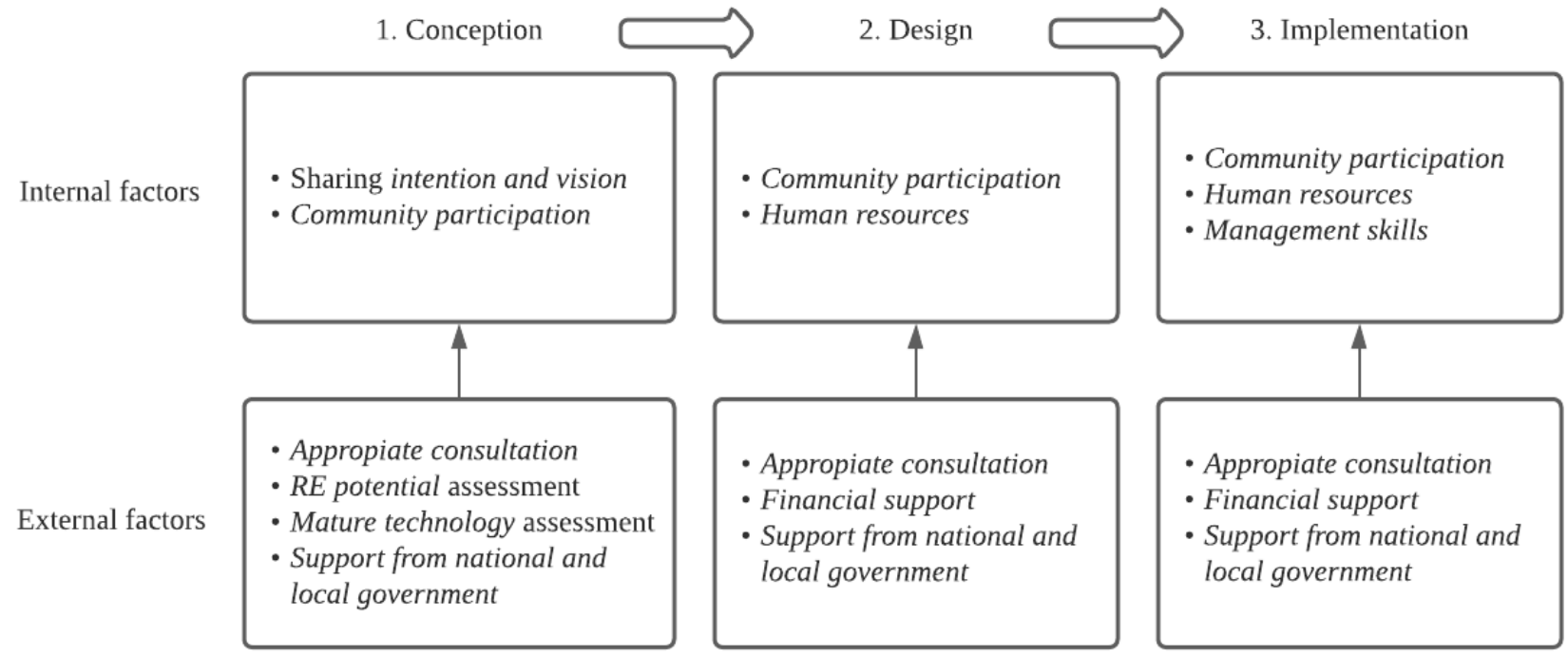

Figure 4. Summary of internal and external conditions and their interaction through a path toward a successful implementation of CRE in Thailand.

\subsubsection{Internal Factors}

A clear "intention and vision" in a community (for both a leader and team members) creates cooperation and unity, accounting for $84 \%$ of the groups. For instance, a cooperative group representative mentioned that "our group has very clear intention and vision on CRE development for improving the local environment and reducing fuel cost of our rubber processing. Therefore, the team members work hard to achieve successful implementation of the project".

"Human resources" is essential in the implementation, accounting for $83 \%$ of the groups. A cooperative group representative, for instance, said that "despite the cooperative having many members and staff, we lack the personnel with expertise in renewable energy technologies. We have to ask the help of experts from outside, which leads to some delay in the implementation".

"Management skills" helps drive the project smoothly, accounting for $94 \%$ of the groups. A community enterprise representative elaborated that "the project must be expertly managed on time, on budget, with knowledge and integration that organizations need". He added that "without this skill, our project would not be successful in terms of the objective, budget, and time".

"Community participation" exerts a significant influence on project implementation because the participation gains social acceptance, accounting for $50 \%$ of the groups. For instance, a biogas network project involved 100 households. The gas produced is supplied through a piping system to the houses of community members. In such a project, community participation plays an essential role because the number of participating households critically affects gas utilization and income. 


\subsubsection{External Factors}

"RE potential" and "mature technology" are significant factors for project development, accounting for $100 \%$ and $92 \%$ of the groups, respectively. Each group mentioned that "without RE resources and technology, the community would not implement CRE. Furthermore, the lack of RE assessment and technology evaluation causes the project to fail".

"Financial support" is a significant factor in a project's implementation, accounting for $84 \%$ of the groups. A grant from the MOEN is the primary source of financial support. The MOEN fund accounts for $30 \%$ to $70 \%$ of the total budget. Subsequently, the community bears the rest. We found that $85 \%$ of the projects raised funds by collecting money from their group members or using the organization's budget. Three cooperative groups and one community enterprise, which represent only $15 \%$ of the projects, borrowed money from banks. Many of them indicated that it was challenging to get a loan for a project with a reasonable interest rate from a commercial bank. Furthermore, a representative of a nonprofit foundation group elaborated that a "foundation organization has no choice but to use the foundation's capital because it is quite difficult for the foundation to borrow money from the bank". Some of them mentioned that "it would be easier for us to implement the project if the government could contact some banks to approve the community loans". Therefore, a financial institution's support is vital for CRE implementation to overcome the initial investment cost burden.

"Appropriate consultation" is necessary to design CRE, accounting for $83 \%$ of the groups. All the groups mentioned that "the projects would not succeed without the support from the expert or academic institution". In these CRE projects, the MOEN provided the community people with technical support from academic advisors. This factor plays an essential role in the initial stage of CRE project development. Community members cannot design concrete CRE systems by themselves due to limited knowledge and skills.

"Support from national and local government" is needed to authorize a project, accounting for $61 \%$ of the groups. Most of the respondents mentioned that "when we create the legal entity in the early development stage, we require support from the relevant government".

\section{Discussion}

The results show that the formation of a CRE's group and the existence of external support contribute to the successful implementation of CRE in Thailand. The characteristics of Thai communities make it easier to formulate groups due to their collectivist mentality and commitment to the traditional roles of each member. However, the formation of a formal organization is necessary as it provides the structure and rules that enable the community to manage the project as a business. Support from the academe helps less experienced CREs by providing technical and financial knowledge. On the other hand, the government provides financial support to implement the projects since most communities have low income.

\subsection{Characteristics of the Community}

Thai farmers with a collectivist culture have a tendency to build long-term relationships and trust, which leads to a shared intention and vision. Their commitment to traditional roles leads to everyone having their own rightful place in society, which fosters community participation in maintaining society. Hofstede reported that Thai cultures exhibit a high power distance and tend to be low on individualism $[35,36]$. Furthermore, these two cultural dimensions (power distance and individualism) relate to the culture of agricultural communities in Thailand because of the kinship principles, which serve as the basic foundation for working together (e.g., rice planting and harvesting are organized around kinship and close friends). Although some traditional agricultural societies are gradually shifting to the agroindustry, collectivist farming vastly remains in Thailand. Thus, Thai agricultural communities can still be considered collectivistic and traditional. Hence, these characteristics lead to (1) effortless formation of groups, (2) willingness to 
accept help from others, and (3) intention to take leadership roles. However, a strong group leader is needed to drive the project's success.

In the UK, internal and vision (4\%) and community participation (5\%) were also identified as success factors, but the percentage was relatively low, suggesting a low impact [17]. In contrast to Thailand's collectivism and commitment to traditional roles, the UK's society is more individualistic and competitive [35,36], which explains the low importance placed on a group's effort. Community spirit and sense of locality and responsibility were also identified as success factors for the community-level project in the Samso Renewable Energy Island, Denmark [13]. Moreover, the longevity of the local people's group was identified as a successful social factor in Scotland [21]. This shows that community participation and intention and vision are important despite the difference in culture.

\subsection{Characteristics of the Group Structure}

Since Thai culture is fundamentally rooted in a kinship society [37], it tends to have unclear business practices, which necessitate a formal structure. On the other hand, individualism in the UK also requires a formal structure to initiate a business. We found that a legitimate organizational structure leads to a successful implementation of CRE, as mentioned in Section 3.1.1. The activity of forming a legal structure sometimes strengthens a group as it provides the opportunity to (1) gather the necessary people with skills needed by a project, (2) establish the rules of an organization, and (3) clarify the duty of members. The legal organization establishes good governance to manage its activities, such as account auditing, annual tax payment, and collective decision making. The results showed that $69 \%$ of the total CRE projects (18 projects) had a formal structure before implementing CRE, as shown in Figure $2 \mathrm{~b}$. A study in the UK also reported that $65 \%$ of the total respondents (354 projects) had a formal structure [17]. In the Thai case, the MOEN required a community to form a legal entity in a project's final application. As a result of forming a formal organization, CRE gained human resources and management skills, which are necessary to manage a project.

\subsection{Knowledge Support}

CREs in Thailand need technical and financial consultation since this kind of project only started in 2013 with support from the MOEN. Communities still do not have the necessary knowledge to implement a project. The MOEN has just implemented a trial of a CRE subsidy program from 2013 to 2016, which suggests that the program is still young. As the MOEN aims at helping agricultural communities to develop CRE, it recognizes that these communities do not have the necessary knowledge about renewable energy. With this in mind, the MOEN has dispatched academic consultants to help communities to develop a CRE project. Initially, the MOEN only contacted Chiang Mai University, and the university used its network to establish a consultation network to support communities in other regions in Thailand.

Despite the efforts of the consultation network, only five universities supported communities across the country due to the limited number of academic organizations in Thailand. It will be tough to support communities once the number of CREs increases in the future. Therefore, there is a need to increase network support. In the UK and Denmark cases, people involved in a project can support each other due to the strong network among CREs and other organizations, such as local authorities, business entities, academic institutions, and nonprofit organizations [13,17]. The study in the UK reported that the average networking of CRE was 2.7 partners per operative project in partnership with other organizations [17], while in the Thai case, it was only 1.15 partners per operative project, as mentioned in Section 3.1.1. In the case of the Samso Renewable Energy Island, Denmark, a strong network with entrepreneurial individuals was identified to effectively support the island's search for new opportunities for CRE development [13]. Therefore, to promote CRE in Thailand, we suggest that the Thai government or academia help CRE 
groups create network support among CRE groups. For example, organizing more AAR activities can create a network among CRE projects.

\subsection{Financial Support}

The participants in the projects are from agricultural sectors that have low income, and most of them need financial support. Actually, 26 CRE projects were implemented with financial support from the government. The project size ranged from USD 3000 to USD 160,000 and USD 40,000 on average per project [9]. With 30\%-70\% subsidy, each project got around USD 28,000. With a farmer's household net income of about USD 2128 per year in 2017 [38], it is insufficient for members to implement a project only with their incomes. This shows the importance of financial support for the success of a project.

Despite the success of these projects, financial support is limited to that of the MOEN, since only $15 \%$ of the participants were successful in borrowing money from financial institutions, as explained in Section 3.2.2. These factors show the limited financial institutes that provide loan for CRE implementation in the country. The Thai government is not entirely decentralized, and as a result, there is minimal local financial autonomy to support CRE. There is a limited grant from the MOEN available for CRE implementation. Moreover, a few soft loans are available for a community to implement a project.

In the UK case, however, since the local government is decentralized, it can directly help CRE projects. Moreover, the UK government created a novel funding mechanism called "Big Society Capital" in 2012 to provide the social sector with affordable financing and build a market for a social investment of social purpose enterprises that expect a social or financial return on investment [17,39]. At the same time, it has a sufficient number of financial institutions that support local activities, with the number of banks totaling about 300 [40]. Thus, the chance to obtain financial support from a bank in the UK is high, which could have led to a significant number of CRE projects in the UK. In contrast, there are only 30 banks in Thailand [41]. Among these small financial institutions, only a few of them provide loans to communities because projects require a low-interest rate. Therefore, the government should establish long-term financial support for CRE. For example, a long-term revolving fund should be created for CRE implementation in Thailand. It is feasible because Thailand already has a revolving fund for the private sector to invest in renewable energy and energy efficiency projects [42].

\section{Conclusions}

The characteristics and success factors for the implementation of the selected $26 \mathrm{CRE}$ projects in Thailand are analyzed. Results reveal that (i) CRE implementation is rooted in geographically bound communities; (ii) a pre-existing group and its legal structure in communities play an essential role in carrying out CRE; (iii) the primary motivation for CRE employment is sustainable development, which focuses on the economic, environmental, and social dimensions; (iv) the internal success factors are intention and vision, human resources, management skills, and community participation, while the external success factors are RE potential, mature technology, financial support, appropriate consultation, and support from the national and local government. It is strongly suggested that external factors, such as financial policy and network support, should be promoted to further facilitate CRE implementation.

Our finding addresses the lack of a comprehensive view on implementing CRE projects in Thailand. Further research is necessary to understand the significant factors influencing CRE implementation in developing countries.

Author Contributions: Conceptualization, N.L. and K.N.I.; methodology, N.L., T.O., H.O., and K.N.I.; software, N.L., T.O., and H.O.; validation, N.L., T.O., H.O., and K.N.I.; formal analysis, N.L.; investigation, N.L. and K.N.I.; resources, K.N.I.; data curation, N.L.; writing—original draft preparation, N.L.; writing-review and editing, N.L., T.O., H.O., and K.N.I.; visualization, N.L.; supervision, K.N.I.; project administration, N.L.; funding acquisition, K.N.I. All authors have read and agreed to the published version of the manuscript. 
Funding: This research received no external funding.

Institutional Review Board Statement: Our study is not applicable.

Informed Consent Statement: Our study is not applicable.

Data Availability Statement: This study did not report any data.

Acknowledgments: The authors are grateful to the communities' leaders and members for sincerely and kindly providing the information required in this study, and especially to the Ministry of Energy and Energy Technology for Environment Research Center, Chiang Mai University, for the great collaboration to get more data for the analysis. Special thanks to Samuel Matthew G. Dumlao for the fruitful discussion, support, and help with English proofreading.

Conflicts of Interest: The authors declare no conflict of interest.

\section{References}

1. Sovacool, B.K. A qualitative factor analysis of renewable energy and Sustainable Energy for All (SE4ALL) in the Asia-Pacific. Energy Policy 2013, 59, 393-403. [CrossRef]

2. Kirubi, C.; Jacobson, A.; Kammen, D.M.; Mills, A. Community-Based Electric Micro-Grids Can Contribute to Rural Development: Evidence from Kenya. World Dev. 2009, 37, 1208-1221. [CrossRef]

3. Hicks, J.; Ison, N. Community-owned RE rural Australia. Rural. Soc. 2011, 20, 244-255. [CrossRef]

4. Del Río, P.; Burguillo, M. Assessing the impact of renewable energy deployment on local sustainability: Towards a theoretical framework. Renew. Sustain. Energy Rev. 2008, 12, 1325-1344. [CrossRef]

5. IRENA. Energy Benefits: Measuring the Economics; International Renewable Energy Agency: Abu Dhabi, United Arab Emirates, 2016. Available online: http:/ / www.irena.org/publications/2016/Jan/Renewable-Energy-Benefits-Measuring-the-Economics (accessed on 16 January 2021).

6. Etcheverry, J. Renewable Energy for Productive Uses: Strategies to Enhance Environmental Protection and the Quality of Rural Life; University of Toronto: Toronto, ON, Canada, 2003; pp. 1-50. Available online: http:/ / citeseerx.ist.psu.edu/viewdoc/summary? doi=10.1.1.614.1572 (accessed on 18 December 2020).

7. Shoaib, A.; Ariaratnam, S. A Study of Socioeconomic Impacts of Renewable Energy Projects in Afghanistan. Procedia Eng. 2016, 145, 995-1003. [CrossRef]

8. Cebotari, S.; Benedek, J. Renewable energy project as a source of innovation in rural communities: Lessons from the periphery. Sustainability 2017, 9, 509. [CrossRef]

9. Chaichana, C.; Wongsapai, W.; Damrongsak, D.; Ishihara, K.N.; Luangchosiri, N. Promoting Community Renewable Energy as a tool for Sustainable Development in Rural Areas of Thailand. Energy Procedia 2017, 141, 114-118. [CrossRef]

10. Fujimoto, T.; Kagohashi, K. Community-led micro-hydropower development and landcare: A case study of networking activities of local residents and farmers in the gokase township (Japan). Energies 2019, 12, 1033. [CrossRef]

11. Walker, G. What are the barriers and incentives for community-owned means of energy production and use? Energy Policy 2008, 36, 4401-4405. [CrossRef]

12. Walker, G.; Hunter, S.; Devine-Wright, P.; Evans, B.; Fay, H. Harnessing Community Energies Harnessing Community Energies: Explaining and Evaluating Community-Based Localism in Renewable Energy Policy in the UK. Glob. Environ. Polit. 2007, 7, 64-82. [CrossRef]

13. Sperling, K. How does a pioneer community energy project succeed in practice? The case of the Sams? Renewable Energy Island. Renew. Sustain. Energy Rev. 2017, 71, 884-897. [CrossRef]

14. Walker, G.; Devine-Wright, P.; Hunter, S.; High, H.; Evans, B. Trust and community: Exploring the meanings, contexts and dynamics of community renewable energy. Energy Policy 2010, 38, 2655-2663. [CrossRef]

15. Hoffman, S.M.; High-Pippert, A. From private lives to collective action: Recruitment and participation incentives for a community energy program. Energy Policy 2010, 38, 7567-7574. [CrossRef]

16. Madriz-vargas, R.; Bruce, A.; Watt, M. A Review of Factors Influencing the Success of Community Renewable Energy Minigrids in developing countries. In Proceedings of the Asia Pacific Solar Research Conference 2015; Egan, R., Passey, R., Eds.; Australian PV Institute: Redfern, Australia, 2015; pp. 1-11. Available online: http://apvi.org.au/solar-research-conference/wp-content/ uploads/2015/12/R-Madriz-Vargos_Peer-Reviewed_FINAL.pdf (accessed on 1 December 2020).

17. Seyfang, G.; Park, J.J.; Smith, A. A thousand flowers blooming? An examination of community energy in the UK. Energy Policy 2013, 61, 977-989. [CrossRef]

18. Guerreiro, S.; Botetzagias, I. Empowering communities-the role of intermediary organisations in community renewable energy projects in Indonesia. Local Environ. 2018, 23, 158-177. [CrossRef]

19. Dragoman, M.C. Factors Influencing Local Renewable Energy Initiatives in Different Contexts: Comparative Analysis: Italy, Romania and the Netherlands. Master's Thesis, University of Twente, Twente, The Netherlands, 2014.

20. Curtin, J.; McInerney, C.; Johannsdottir, L. How can financial incentives promote local ownership of onshore wind and solar projects? Case study evidence from Germany, Denmark, the UK and Ontario. Local Econ. 2018, 33, 40-62. [CrossRef] 
21. Haggett, C.; Creamer, E.; Harnmeijer, J.; Parsons, M.; Bomberg, E. Community Energy in Scotland: The Social Factors for Success; CXC; University of Edinburgh: Edinburgh, UK, 2013; pp. 1-25.

22. Wüste, A.; Schmuck, P. Bioenergy villages and regions in Germany: An interview study with initiators of communal bioenergy projects on the success factors for restructuring the energy supply of the community. Sustainability 2012, 4, 244-256. [CrossRef]

23. Macabebe, E.Q.B.; Guerrero, R.C.; Domdom, A.C.; Garcia, A.S.; Porio, E.E.; Dumlao, S.M.G.; Perez, T.R. A review of communitybased solar home system projects in the Philippines. MATEC Web Conf. 2016, 70, 12002. [CrossRef]

24. Rolando, M.-V.; Anna, B.; Muriel, W.; Yuri Alvarado, R. Energy with Development: 50 years' Experience of Communitydriven Rural Electrification and Future Challenges for COOPEGUANACASTE in Costa Rica. In Proceedings of the Asia Pacific Solar Research Conference 2016; Egan, R., Passey, R., Eds.; Australian PV Institute: Redfern, Australia, 2016; pp. 1-12. Available online: http:/ / apvi.org.au/solar-research-conference/wp-content/uploads/2017/02/R-Madriz-Vargas-A-Bruce-M-Watt-and-YAlvarado-Rojas-Energy-with-Development-in-Costa-Rica.pdf (accessed on 1 December 2020).

25. Kitisittichai, P.; Aruninta, A. Best Management Practices for Sustainability in a Small-scale Community Renewable Energy: Sathya Sai School, Thailand. Appl. Environ. Res. 2015, 37, 93-105. [CrossRef]

26. Marquardt, J.; Delina, L.L. Reimagining energy futures: Contributions from community sustainable energy transitions in Thailand and the Philippines. Energy Res. Soc. Sci. 2019, 49, 91-102. [CrossRef]

27. Seyfang, G.; Haxeltine, A. Growing grassroots innovations: Exploring the role of community-based initiatives in governing sustainable energy transitions. Environ. Plan. C Gov. Policy 2012, 30, 381-400. [CrossRef]

28. Wirth, S. Communities matter: Institutional preconditions for community renewable energy. Energy Policy 2014, 70, 236-246. [CrossRef]

29. Elo, S.; Kyngäs, H. The qualitative content analysis process. J. Adv. Nurs. 2008, 62, 107-115. [CrossRef] [PubMed]

30. Ellis, S.; Davidi, I. After-event reviews: Drawing lessons from successful and failed experience. J. Appl. Psychol. 2005, 90, 857-871. [CrossRef] [PubMed]

31. Adams, W.C. Conducting Semi-Structured Interviews. In Handbook of Practical Program Evaluation; Newcomer, K.E., Hatry, H.P., Wholey, J.S., Eds.; John Wiley \& Sons, Inc.: Hoboken, NJ, USA, 2015; ISBN 9781119171386.

32. Iemsomboon, P.; Tangtham, N. Problems and barriers on SHSs management in Thailand's rural areas based on SWOT analysis. Energy Procedia 2014, 56, 598-603. [CrossRef]

33. GÜREL, E.; TAT, M. Swot Analysis: A Theoretical review. J. Int. Soc. Res. 2017, 10, 994-1006. [CrossRef]

34. NordNordWest. Paul_012 Thailand Provinces Map en. Available online: https://en.wikipedia.org/wiki/File:Thailand_ provinces_en.svg (accessed on 23 April 2021).

35. Country Comparison-Hofstede Insights. Available online: https://www.hofstede-insights.com/country-comparison/thailand, the-uk/ (accessed on 20 April 2021).

36. Srikes, M.; Louvieris, P.; Collins, C. The impact of culture on mobile phone purchasing: A comparison between thai and british consumers. In Proceedings of the 17th European Conference on Information Systems, ECIS 2009, Verona, Italy, 8-10 June 2009. Available online: https: / /aisel.aisnet.org/ecis2009/408 (accessed on 20 April 2021).

37. Kuwinpant, P. Thai Society and Culture; Nagoya University: Nagoya, Japan, 2002.

38. Office of Agricultural Economics. Indicators of Socio-Economic Conditions of Agricultural Households. Available online: https:/ / www.oae.go.th/assets/portals/1/files/socio/socio10june63.pdf (accessed on 29 April 2021).

39. Policy Guide to Scaling Social Innovation 2013-Reports-World Economic Forum. Available online: https:/ / reports.weforum. org/social-innovation-2013/big-society-capital-united-kingdom/?doing_wp_cron=1618670113.8847661018371582031250 (accessed on 17 April 2021).

40. List of Banks in the UK-Top UK Banks. 2018. Available online: https://www.relbanks.com/europe/uk (accessed on 18 December 2020).

41. Number of All Branches and Service Point of Commercial Bank in Thailand. 2020. Available online: https://www.bot.or.th/ App/BTWS_STAT/statistics / BOTWEBSTAT.aspx?reportID=904\&language=ENG (accessed on 18 December 2020).

42. Energy For Environment Foundation. ESCO Revolving Fund. Available online: http://www.efe.or.th/escofund.php?task= \&sessid=\&lang=en (accessed on 30 March 2021). 